ARE PLANNING METHODS CULTURALLY NEUTRAL?

EXAMINING HOW PLANNERS READ MULTICULTURAL LANDSCAPES

by

Leah Frances Bennett Cooke

BA, University of Waterloo, 2013

A Major Research Paper

presented to Ryerson University

in partial fulfillment of the requirements for the degree of

Master of Planning

in

Urban Development

Toronto, Ontario, Canada, 2015

(C) Leah Cooke 2015 


\section{Author's Declaration for Electronic Submission of a MRP}

I hereby declare that I am the sole author of this MRP. This is a true copy of the $\mathrm{MRP}$, including any required final revisions.

I authorize Ryerson University to lend this MRP to other institutions or individuals for the purpose of scholarly research

I further authorize Ryerson University to reproduce this MRP by photocopying or by other means, in total or in part, at the request of other institutions or individuals for the purpose of scholarly research.

I understand that my MRP may be made electronically available to the public. 


\title{
ARE PLANNING METHODS CULTURALLY NEUTRAL? EXAMINING HOW PLANNERS READ MULTICULTURAL LANDSCAPES
}

\author{
(C) Leah Cooke, 2015 \\ Master of Planning \\ in \\ Urban Development \\ Ryerson University
}

\begin{abstract}
Are traditional observational planning methods applicable to the growing range of contemporary urban settings? These methods, which include the approaches of Kevin Lynch, Jane Jacobs, William Whyte, Allan Jacobs, and Jan Gehl, were identified and analysed in an ethnocultural, suburban context. Specifically, they were applied to Pacific Mall in Markham, which was selected as a case study. Observations were compared to Dr. Zhixi Zhuang's in-depth research, who determined what was and was not missed. This comparison determined that while the observational methods were able to read the landscape, there was cultural information not possible to establish through observation alone. Practicing planners need to better consider this cultural information when analysing space.

This includes the culture of the space, the intended users of the space, legibility for these users, and what information to include in reports to better plan for places that are culturally unknown to the planners responsible for them.
\end{abstract}

Key words:

planning; observation; ethnicity; suburbs; planning methods. 


\section{Acknowledgments}

Foremost, I cannot find words to express my gratitude to Dr. Pamela Robinson for her unending support of this project, which wouldn't be possible without her vision. It has been a pleasure and a privilege to work with her, both on this project and throughout my time at Ryerson. I would also like to thank Dr. Zhixi Zhuang for her invaluable feedback and guidance.

Further, I would like to thank my mother for putting up with me at my worst and supporting me so that I could strive to be my best. Thanks as well to my friends, especially Evan Manning and Alicia Kingdon, for keeping me sane through the past two years. 


\section{Table Of Contents}

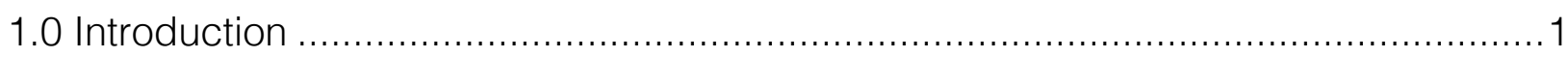

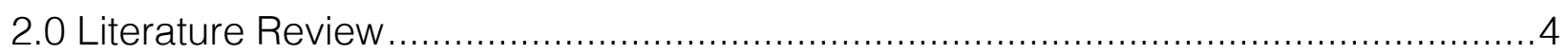

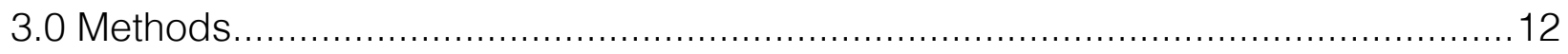

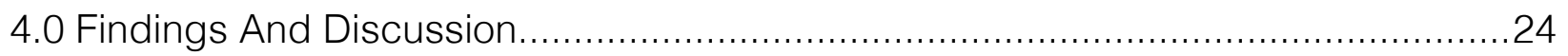

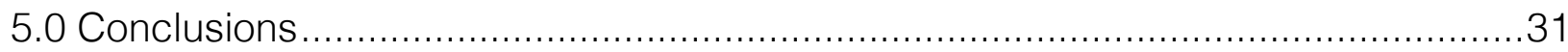

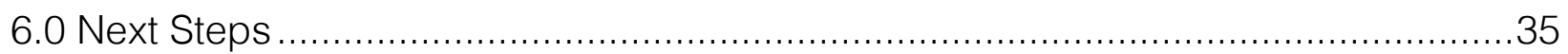

\section{Table Of Figures}

Figure 1: Pacific Mall Parking Lot...................................................... 14

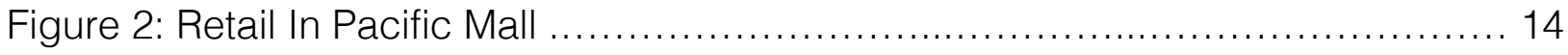

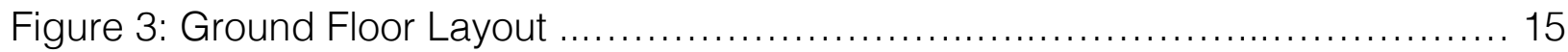

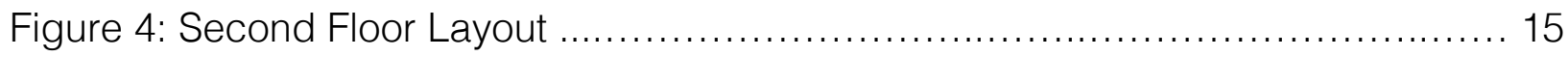

Figure 5: Overview Of Observational Methods …................................. 16

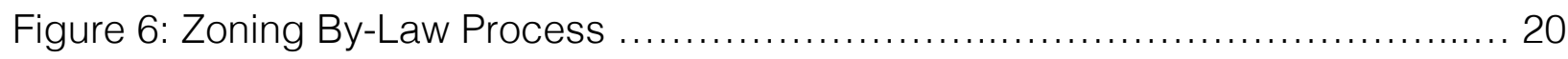

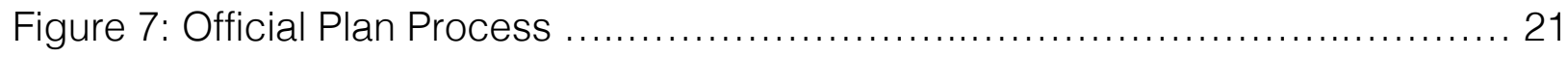

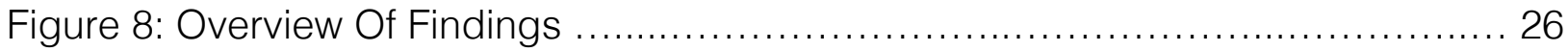




\subsection{Introduction}

In his 1985 book Looking at Cities, Allan Jacobs asks a vital question, "Even if one can usefully learn from observation in the United States, can an American read the clues in Italy or China or South America?" (Jacobs, 1985, p. 108). This question, still relevant today, is one that attempts to determine whether the methods we learn in Western planning schools apply to different urban contexts. How do planners learn about spaces that they don't know? And how does this knowledge translate to other environments?

Contemporary planning practice operates within tight timeframes and budgets. In Toronto, local neighbourhood planning offices used to allow citizens direct access to the community planners responsible for the planning of their neighbourhood; these offices were closed in the 1990s and amalgamated in City Hall (Kane, 2013). This detachment often means that planners are removed geographically from the neighbourhoods they plan, as well as much more difficult to contact for citizens. Planners are also asked to plan within increasing geographic areas, meaning that they are less likely to work or live in the areas for which they are responsible. Planning firms routinely consult in and for cities and regions far removed from their offices- meaning a limited exposure to the community for which planners need to make decisions. This new reality is summarized by Abramson (2005), who affirms that, "As greater numbers of planning consultancies practice across national borders, the local embeddedness of actual planning conditions presents a major problem for the training of planning professionals" (p. 100-101).

In addition to time and budgetary constraints, planners are also facing built form with which they are unfamiliar. Newer forms of building, including increasingly higher densities as well as suburban and New Urbanist developments, mean a more complicated and nuanced urban landscape which planners are regularly asked to analyze and plan (see: Gordon \& Janzen, 2013; Dunham-Jones, \& Williamson, 2011). 
Further, cities around the world are experiencing an unprecedented influx in globalization; the term Global City is now being used to describe this new reality (Sassen, 2001). It speaks to a new, truly multicultural environment that further complicates the urban setting, creating further nuances for planners to navigate and understand. This combination of factors means that planners are regularly confronted with urban contexts with which they are unfamiliar.

Cities in North America have been built overwhelmingly suburban in form for the last half-century; Gordon and Janzen classified $80 \%$ of Canadian city form as suburban, including $86 \%$ of Toronto's CMA (Gordon \& Janzen, 2013). Research has come to light more recently that points to the shortcomings of suburban development for reasons including health, sustainability concerns, and quality of life issues (see: Talen, 2005; Turcotte, 2008). In light of these shortcomings it would seem logical to study these developments to determine if, how, and why these neighbourhoods are not functioning in the way that they should. The standard mapping and observational methods planners use, however, refer almost exclusively to urban as opposed to suburban form.

Based on these new realities, it seems an important time to revisit Jacobs' question, but apply it to the changing landscape of cities everywhere. Do planners' methods apply to suburban contexts? If traditional observational methods find issues with the environment in non-traditional urban contexts, does that imply an issue with the built form, or with the applicability of the method itself? And more generally, are the tools that planners use to evaluate unfamiliar spaces appropriate? If they are, how generally applicable are they?

Despite the changing urban landscape and growing separation between a planner and the spaces they plan, decisions regarding the quality and future of public spaces remain an important part of a planner's job. These new realities raise a number of questions: how do planners learn about and immerse themselves in spaces? What 
methodological tools do they use? And do these tools hold true in contemporary contexts? We have a new plurality of form and space that has emerged from a context that differs from the one in which the tools were created. Do these methods still hold up today, are new tools needed, or are adaptations required to contemporize these methods?

In order to study the effectiveness of these tools in a contemporary urban planning practice, I will first conduct a literature review to determine how the methods have been and continue to be used in planning practice and academic research. I will then apply the tools to a suburban ethnocultural context. I will compare my findings with in depth research to determine what elements of the space I was able to detect through the use of the methods, and what was missed. Based on these differences, I will make recommendations for applied planning practice so that urban planners can better understand unknown places. 


\subsection{Literature Review}

\section{Traditional Planning Observational Methodologies}

In the first half of the twentieth century, urban planning was an expert driven practice. "Planners" made master plans, with public consultation notably absent from their decision-making. In response, Jane Jacobs' 1961 paradigm shifting critique of planning called for a better understanding of the impact that planning decisions have on the use of built form. The separation between planner and citizen, and subsequent push back by citizens and urbanists like Jacobs, resulted in a drastic change in the way that cities were planned and how the planning process was viewed by planners and citizens. Part of this shift was the creation of observational methodologies that planners could use to determine how urban spaces were used by the people who interacted with and used the spaces.

Most notably, Kevin Lynch (1960, 1984), Jane Jacobs (1961), William H. Whyte (1980), Allan Jacobs $(1985,1993)$, and Jan Gehl $(2010,2013)$ have created methods that are widely used and replicated; their methods use different techniques to observe people within urban settings. Jane Jacobs (1961) focused on the need for planners to observe the urban environment, but has been most criticised for her lack of concrete methods- she included no step-by-step instructions in her books. Kevin Lynch (1960) has provided the most concrete mapping tool, referred to as Lynchian analysis. His analysis revolves around citizen generated mental mapping and focuses on how legible different urban environments are to users. His mapping uses nodes, landmarks, districts, edges and paths to define how they use their neighbourhoods and cities. William Whyte (1980) created the most exacting quantitative methods, using video recording, grids, graphing and fastidious counting techniques to determine how people in New York City used public plazas. Allan Jacobs (1985) focused on clues, listing the visual evidence that a planner can look for in an environment to better understand important details of the built form as well as who lives, works and plays 
there. Jan Gehl (2013) has created methods for observing how people use public spaces. His approach is similar to Whyte's in that they read people's behaviour, but instead measures details like walking speed and route tracing, and observes select random people instead of taping entire days to analyse.

There is an important differentiation that is required between observational methodologies and those stemming from urban design. Many authors within the discipline of urban design have written about what a good space should include or exclude. Authors including Appleyard (1970), Alexander (1977), Trancik (1986), and Bentley (1985) are the classics this field, with many more authors building on their works and providing contemporary examples and updates, including the work of those such as Tibbalds (2012) and Carmona (2013). The findings of these authors centre wholly around the creation of quality spaces, both within a larger community, along a street, and within the homes themselves.

While urban design literature speaks extensively to what constitutes good urban form, it lacks discussion around observation or how to judge existing urban forms to determine how these design elements interact with the users. The observation methods discussed here, on the other hand evaluate urban spaces based on varying criteria around the success of design elements and use characteristics of public urban spaces. They begin with the observation, and, based on these observations, reach conclusions as to what design elements makes an urban place successful. It is therefore difficult to separate these observational methods from urban design, and many authors refer to them as though they were a single discipline. It is important to separate them for the purposes of this paper, however; in attempting to determine how planners observe spaces, it is necessary to only review observational methodologies. The field of urban design doesn't speak to observational techniques, and is therefore outside of the scope of this project. 


\section{Applying the Methods to Different Types of Urban Form}

These methods were created for urban landscapes at a time when these landscapes were simpler and more uniform. Cities were more similar in form, and users were less diverse. Now, however, this is becoming less and less the case. Cities vary across a wider spectrum of built form, from exurban to suburban to urban with variations in between. The user of cities are diversifying as our populations become more varied, especially in a place like Toronto (Zhuang, 2013). This raises an important question: in this complicated and diverse landscape, do our traditional planning methods still work? A review of the literature will attempt to analyze the differences of place and determine where others are using these observational methods.

\section{Cultural Places and Uses of Urban Form}

An important area of literature to understand is that of planning for different cultural groups; Understanding how the form interacts with the users of the space and how that differs culturally is increasingly necessary for planners to understand (Burayidi, 2003). Research has been conducted throughout North America to better understand the relationship between one's culture and ethnicity as well as the use of public urban spaces. Authors including Burayidi, $(2000,2003)$ researched broader implications of the increasing mix of residents within a single city, and the difficulties of meeting this new variety of needs on a municipal level. Others have studied the more immediate effects of increasing multiculturalism, including: a study of how different cultural groups use urban parks in Los Angeles, finding the needs of Asian community members to differ widely from African-Americans (Loukaitou-Slideris, 1995); a discussion of the 'ethnoburb' and its existence in Toronto, a term describing the recent trend of ethnic communities settling in traditionally middle-class Caucasian suburban neighbourhoods (Wang \& Zhong, 2013); the mapping of ethnic enclave locations in Toronto, finding majority groups mixed with others (Qadeer, Agrawal, \& Lovell, 2010); and the increase in ethnic retailing in Toronto, where Zhuang (2013) points to 
deficiencies in current planning policy that detract from the success of places such as Pacific Mall in Markham. This literature points to a fundamental discrepancy between the growing need for appropriate public amenities for our increasingly diversifying population(s) and the necessary supporting policy and understanding of requirements on a municipal level. No articles on using traditional observational methods in these cultural contexts were found.

\section{Urban and Suburban: What is the Difference and Why Does that Matter?}

Another important area of literature is the differences between urban and suburban spaces. While the definition of suburban seems obvious, it seems to be particularly difficult for researchers in the field to agree on a definition; Forsyth states, "Even among urban scholars, then, there is no consensus as to what exactly constitutes a suburb. The plethora of meanings expands when one includes popular and media accounts" (2012, p. 170). For the purposes of this research, however, suburban form can be assumed to differ from urban form based on increased car dependence, separation of land uses and low density. Importantly, it is clear that there are categorical differences between these built environments that result in different use patterns. This is important in determining how changes in use would result in changes in how a space can or can't be observed.

Despite the importance of determining the different use of urban and suburban form, there appears to be a general lack of concrete research within the planning and design disciplines that points to exactly why or what parts of suburban development are unsuccessful. This is surprising, given the seemingly high level of general acceptance of anti-suburban sentiment in the urban planning community. Outcomes such as long commute times and lack of diversity in uses are the most often cited research, including studies pointing to health concerns stemming from a lack of physical activity in suburban census tracts as well as a greater dependence on cars (see: Turcotte, 2008 \& 2009). 
While these high-level discussions of suburban development exist, the literature seems to be lacking a more detailed analysis of the particular changes required/shortcomings of suburban built form in a way that would be helpful for this research. The best example is the research done by Owens (1993), who has compared zoning, parcel patterns, photographs of public areas, building patterns, and street patterns to find the key differences between urban and suburban neighbourhoods. His paper concludes with the need for "there is a need to translate these rather loose descriptions into a set of environmental variables that can be more precisely measured and described" (Owens, 1993, p. 134).

Further, patterns of how people interact with suburban built form have been largely ignored within academic planning journals. It is therefore difficult to assess the utility of these methodologies within this largely unexplored space. In order to fully determine the ability of urban based methodologies to properly assess suburban form, it would also be necessary to determine the differences between these forms, and why contemporary planners generally accept that these forms of development are unsuccessful.

\section{Can we read third spaces the same ways we read other spaces?}

Finally, the notion of third places is relevant to the discussion of public spaces. Oldenburg defines third places in that, "Third places exist outside the home and beyond the "work lots" of modern economic production. They are places where people gather primarily to enjoy each other's company" (1982, p. 269). These places are important because they exist outside of the rest of our daily environments which revolve around highly structured social roles- home, school and work; people have been found to value these places, as they have a wide desire informal social gathering places. Bars and coffee shops are the most common form of neighbourhood third place, with malls often serving a similar function (Oldenburg \& Brissett, 1982). Starbucks has famously marketed itself as a third place, increasing public 
understanding around the existence and importance of these places (see:

Rosenbaum, Ward, Walker, \& Ostrom, 2007; Jeffres, Bracken, Jian, \& Casey, 2009).

The question of whether or not we can observe these places using traditional planning methods is an interesting one. Many public spaces, for which the methods were largely created, are third places and therefore they should be easily observable. This is particularly true for Whyte, whose observations were first done in public plazas in New York, places which contain many of the characteristics of a third place.

\section{What is the state of our knowledge about how to read/see landscapes?}

Based on the wide range of urban environments, a natural question arises around whether we can apply these tools to ethnocultural, suburban third places. However, given the current lack of research available on the application of these methods to spaces such as these, it is one that seems impossible to answer with a literature review alone.

There is a surprising lack of academic literature regarding the continued use of these methods in planning practice; the few works discovered are discussed here. The work and research of William Whyte has been continued by the Project for Public Spaces (PPS) out of New York City. PPS works on ways to better enliven public spaces but focus on placemaking initiatives, including 'How to Turn a Place Around' book (PPS, 2000), with less focus on the continuation of Whyte's observational methods. Lynch's method appears to be the most cited to date(see: Ford, 1999; Smith et al., 2014). A study in Los Angeles compared the mental maps of Caucasian, AfricanAmerican, and Latino residents using a Lynchian format (Hayden, 1997); more recently, Lynch has been applied to new urbanist developments in order to judge this new way of building residential communities (Ford, 1999).

Another major gap in academic literature is the one that speaks to the contemporary practice of planning professionals. All of the research and literature discussed here lies largely within the research conducted by planning academics, as 
is to be expected, but doesn't touch on the actual practice of planning professionals. Because planning practice and academia is so removed, there isn't a lot of academic research on what methods practicing planners use to read/see the landscapes where they work. Some insight into contemporary methods are given by Talen (2011) in regards to walkability research, using a direct comparison of on the ground observation to the use of GIS and Google map technology; she finds that it is possible to determine similar outcomes using both methods. This addition of technology begs the question of whether is this also true for planners in their practice. Do practicing planners use these new tools or do they continue to use traditional observational methods?

It is difficult to speak to how the use of these methods has or hasn't continued and evolved over the years by planners and planning educators within the discipline. And what does this lack of academic attention mean/signal? It could indicate that the methods are functioning as they should, but could also speak to a gap in communication between practicing planners who need new tools and the academics who could provide them. The lack of literature around both these built forms in general and absence of research on the application of traditional planning methods to these places makes it impossible to answer this question from a literature review alone.

\section{What does this mean?}

The question of how planners observe and judge the city elements over which they have control is one that stems back to Jane Jacobs: do planners make decisions based purely on what is allowed in the current legislation, formed by the contemporary beliefs of academics and practitioners in the field? Do they spend time determining how those who live within the space actually use it? Or some combination of these approaches?

Jacob's (1961) critique of the professional field of planning was that planners believed they knew what was best for the community. The most famous example of 
this was her fight against Moses and his plans for an expressway through Greenwich Village (Jacobs, 1961). Contemporary planning has moved away from this approachpublic consultations around many planning issues are held, and it is generally acknowledged that the field has moved away from this top-down approach to planning. While we have moved the planning practice forward, why haven't we actively pushed forward our methods?

The planning process is structured around a reliance on relevant policy documents (Official Plan and Zoning By-Law, in particular), as well as a planner's professional opinion, and frequently, public participation. The question brought forward by this gap in literature becomes whether or not we are arming contemporary urban planners with the tools with which they are able to make the sound professional planning recommendations for the communities in which they are planning.

Because academic planning literature and applied contemporary practice are so far removed, it is difficult to track or trace how these methods have been used or are used today. This leads to a lack of clarity about how planners use these tools to understand an unknown space. If observations are completed, Lynchian or otherwise, they are not included in City Planning staff reports or in consulting documents, focusing instead on final conclusions and design recommendations.

Given this disconnect between applied planning practice and academic literature, it is difficult but important to determine whether the traditional planning observational methodologies still apply today, and whether they apply to the wider range of urban realities we are faced with in the contemporary city. There exists a knowledge gap around applied planning practice from the academic community, and vice versa. In this particular context, it is necessary to determine how contemporary planners learn about spaces they don't know and judge whether or not these tools are still applicable, or whether they require a contemporary update to bring them into line with the needs of the twenty first century city. 


\subsection{Methods}

In order to assess the continued utility of these methodologies, I will apply them to a physical space that I am unfamiliar with. I will focus my research on the observational and evaluative methods of urban spaces as proposed by the $20^{\text {th }}$ century planners Lynch, Jacobs, Whyte, Jacobs and Gehl. These authors form the backbone of the planning field's current understanding of how to observe public spaces, including their various methods of what observational techniques to use and what clues or elements to look for in the environment. By determining how these methods apply to an ethnocultural, suburban third place, this research will attempt to create a first step in bridging the current gap in knowledge about the continued use of observational methods.

\section{Case Study Site Selection: Pacific Mall}

In order to test whether traditional planning methodologies stand up in unfamiliar or new places, I will apply these observational techniques to a space which is unknown to me, one that is suburban, ethnocultural and a third place. Specifically I will be looking at Pacific Mall, located at Steeles Ave. and Kennedy Rd. in Markham, Ontario. Steeles is southernmost boundary of Markham, with the mall on the boundary of Markham and Toronto. This mall is touted as "The Largest Chinese Indoor Mall in North America" on their website, with over 500 stores (Pacific Mall, n.d.). The Mall opened in 1997, and occupies the space formerly held by Cullen Country barn; it has both outdoor and indoor parking (over 1,500 spots total). The mall is an official Canadian Tourist Attraction, and is therefore exempt from Ontario laws requiring the closing of tmalls on holidays; accordingly, it is open 365 days a year, and is the only mall open in the GTA on Christmas day (Consiglio, 2012). It is run with condominium style ownership, in that store owners own (or sublease) their units. See Figures 3 and 4 for layout. 
I have selected this location in particular for a number of reasons. First, it is a suburban, ethnocultural third place and as it is located within the GTA is accessible to me geographically. Further, it is from and catering to a culture that I am relatively naive of, and is a physical space that I am completely unfamiliar with. Despite growing up in Toronto I have never been there before. Finally, it has been studied in detail by Dr. Zhixi Zhuang (2013). Her research focuses on ethnic retailing, and she has extensively studied Pacific Mall in particular. Her research focused around the role planners had in the creation of the ethnic retail space; for Pacific Mall this only included site plan approval that included parking and traffic concerns (Zhuang, 2013).

My analysis will include assessing the site using the observational methods and recording my initial findings. I will then compare them to Zhuang's previous research (2013) informed by in depth research of the mall to determine what information was missed by these methods. From these discrepancies, I will come up with theoretical questions followed by pragmatic suggestions for practising planners to better overcome the potential shortfalls of the methods. 


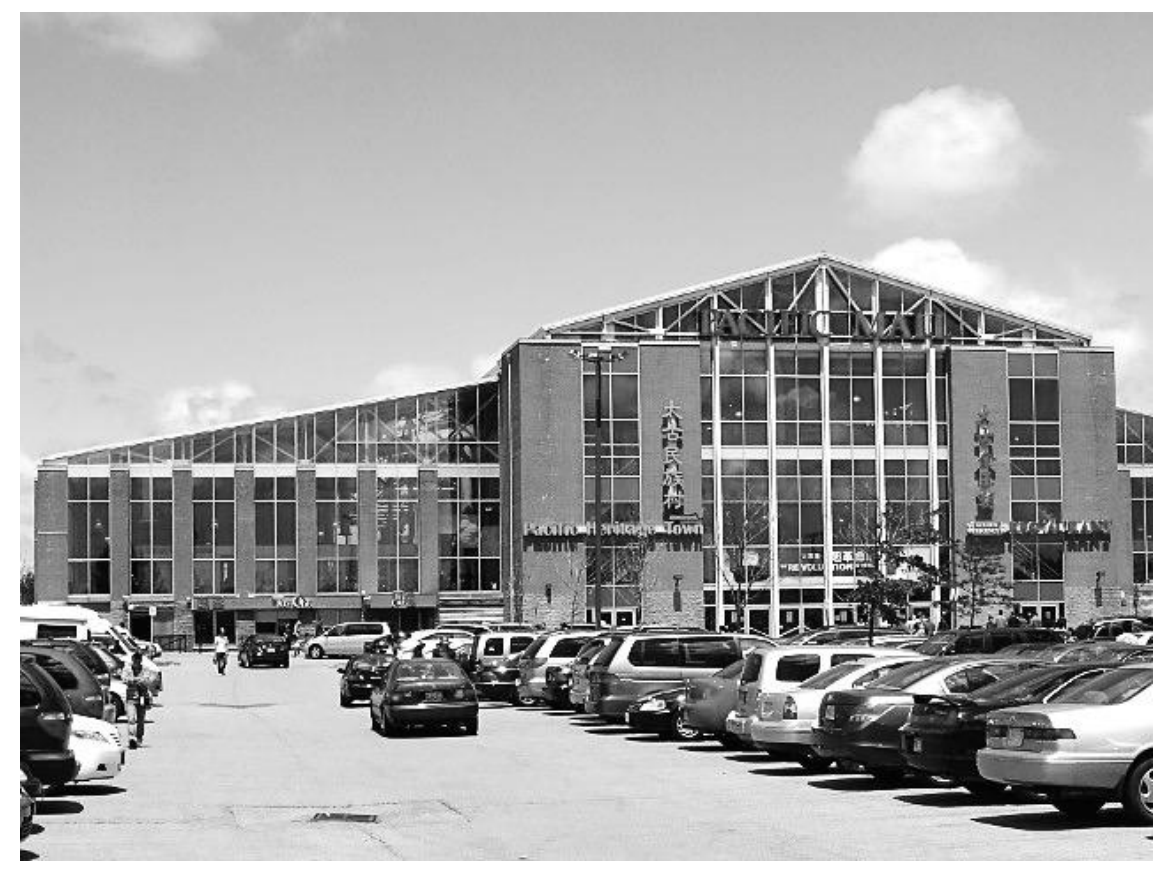

Figure 1. Pacific Mall parking Lot

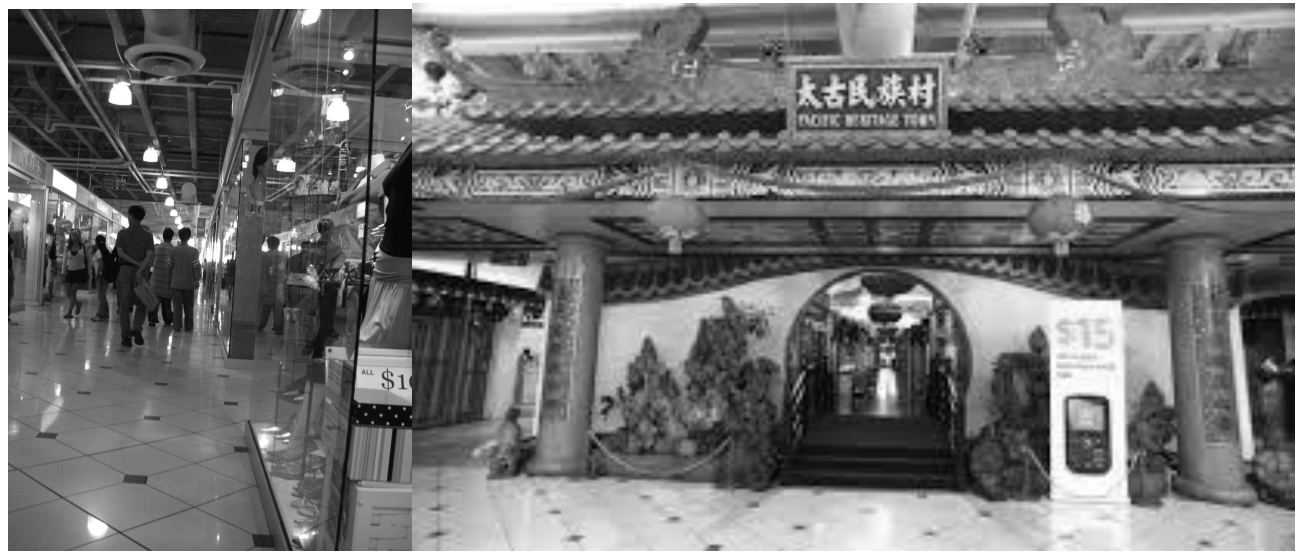

Figure 2. Retail in Pacific Mall 


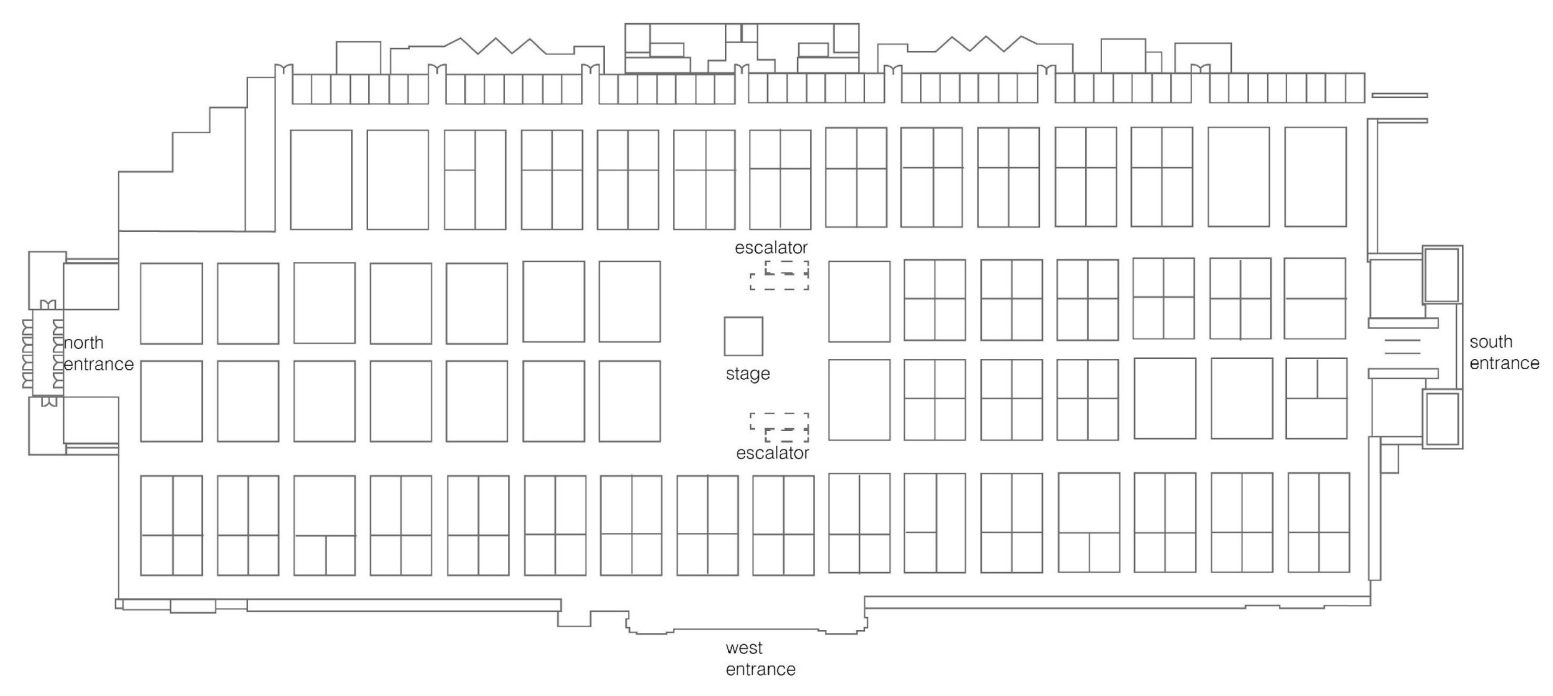

Ground Floor

Figure 3. Ground Floor Layout

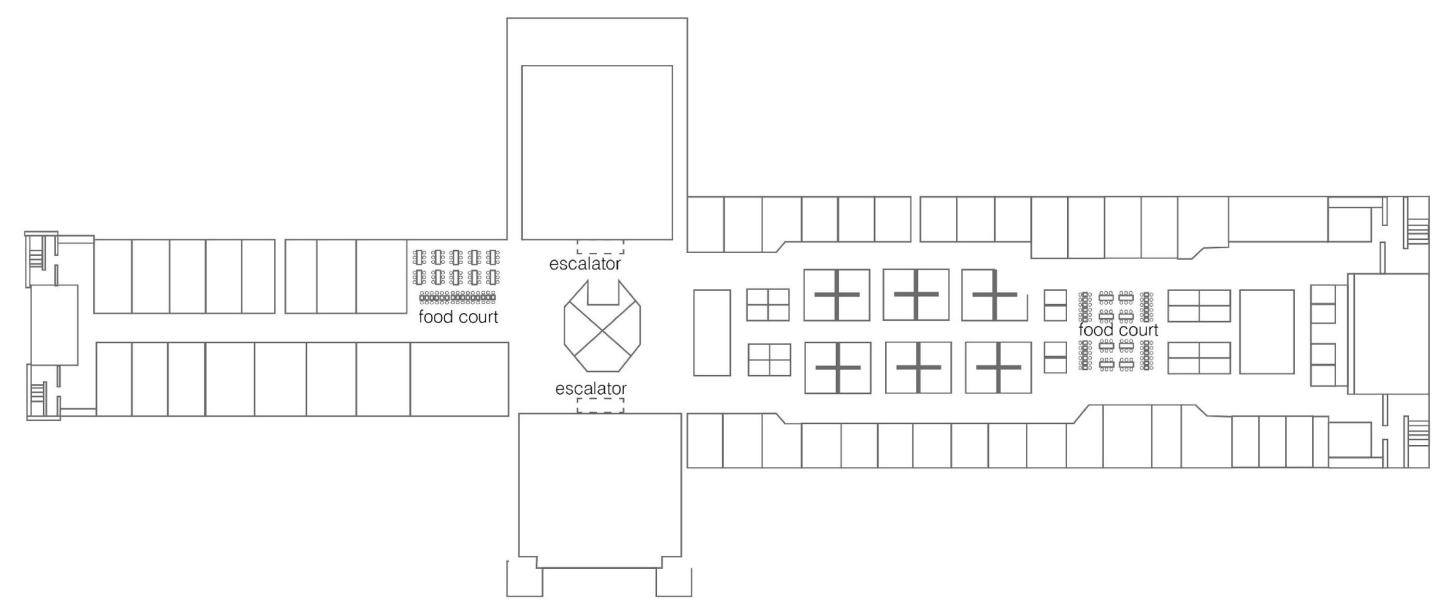

Second Floor

Figure 4. Second Floor Layout 
The Application of Observational Methods

\begin{tabular}{|c|c|c|c|}
\hline Author & $\begin{array}{l}\text { Overview } \\
\text { Observational Method }\end{array}$ & $\begin{array}{l}\text { What is Method } \\
\text { Looking for }\end{array}$ & How I Used the method at Pacific Mall \\
\hline Lynch & $\begin{array}{l}\text { Method focuses around } \\
\text { legibility of spaces- } \\
\text { observations are meant } \\
\text { to measure how legible } \\
\text { and usable spaces are } \\
\text { by the intended users. } \\
\text { Mapping method } \\
\text { focusing on paths, } \\
\text { nodes, edges, districts } \\
\text { and landmarks. }\end{array}$ & $\begin{array}{l}\text { Legibility of } \\
\text { space- how do } \\
\text { users read } \\
\text { different elements } \\
\text { of the space? } \\
\text { How legible is it? }\end{array}$ & $\begin{array}{l}\text { T conducted my own Lynchian analysis, } \\
\text { basing on observation noting how people } \\
\text { appear to use the space. This method, used } \\
\text { in my planning classes and others (Smith, } \\
\text { Warner, Fioretti \& Meschiari, 2014) is one } \\
\text { which is generally accepted as a good initial } \\
\text { look at a space when there isn't time or } \\
\text { need to interview community members. }\end{array}$ \\
\hline $\begin{array}{l}\text { J. } \\
\text { Jacobs }\end{array}$ & $\begin{array}{l}\text { Method was bottom up } \\
\text { and inductive and } \\
\text { largely exploratory. She } \\
\text { was an activist who } \\
\text { critiqued planners. }\end{array}$ & $\begin{array}{l}\text { Actual use } \\
\text { patterns of urban } \\
\text { streets. }\end{array}$ & $\begin{array}{l}\text { Because Jacobs gave little actual advice } \\
\text { around observational techniques, and the } \\
\text { context of an indoor mall is very outside of } \\
\text { her scope, I did not use her methods for } \\
\text { Pacific Mall. }\end{array}$ \\
\hline Whyte & $\begin{array}{l}\text { Method focused on } \\
\text { timed observations, } \\
\text { noting the location and } \\
\text { duration that people } \\
\text { use sitting spaces or } \\
\text { stop in conversation. } \\
\text { Techniques included } \\
\text { video recording and in } \\
\text { person observation, } \\
\text { with systematic notation } \\
\text { techniques, recording } \\
\text { activity in public spaces } \\
\text { on maps with grids. }\end{array}$ & $\begin{array}{l}\text { What elements of } \\
\text { spaces most } \\
\text { affected the use } \\
\text { of the space, and } \\
\text { which ones } \\
\text { increased or } \\
\text { decreased } \\
\text { people's wish to } \\
\text { use the sites. }\end{array}$ & $\begin{array}{l}\text { Whyte's methods are the most immediately } \\
\text { applicable to this context. Only his methods } \\
\text { address indoor spaces, offering four } \\
\text { characteristics with which to judge a space: } \\
\text { 1) sitting 2) food 3) retailing 4) toilets. } \\
\text { Further, the majority of his methods centre } \\
\text { on pure observation and counting/timing the } \\
\text { users of the space. I did not use } \\
\text { videotaping, but noted where people were } \\
\text { sitting, and noted where people were } \\
\text { standing. }\end{array}$ \\
\hline $\begin{array}{l}\text { A. } \\
\text { Jacobs }\end{array}$ & $\begin{array}{l}\text { Method emphasizes the } \\
\text { importance of } \\
\text { architectural styles, } \\
\text { street layout, traffic, } \\
\text { people, activities, and } \\
\text { business type. }\end{array}$ & $\begin{array}{l}\text { Uses clues to } \\
\text { reach } \\
\text { conclusions } \\
\text { about the overall } \\
\text { condition and } \\
\text { demographic } \\
\text { information about } \\
\text { the observer's } \\
\text { surroundings. } \\
\text { and the people } \\
\text { that may live } \\
\text { there. }\end{array}$ & $\begin{array}{l}\text { Many of Jacobs' clues are not applicable } \\
\text { due to Pacific Mall's indoor design and } \\
\text { uniform construction. The most applicable } \\
\text { clues to Pacific Mall are: 1) architectural } \\
\text { style 2) level of repair 3) signs (of stores and } \\
\text { within the mall) 4) people 5) the commercial } \\
\text { centre as a whole. I took notes on these } \\
\text { categories in particular, in an attempt to } \\
\text { make inferences about the particulars of } \\
\text { these clues. }\end{array}$ \\
\hline Gehl & $\begin{array}{l}\text { Method uses eight } \\
\text { particular approaches } \\
\text { for urban observations: } \\
\text { Counting, Mapping, } \\
\text { Tracing, Tracking, } \\
\text { Looking for traces, } \\
\text { Photographing, } \\
\text { Keeping a diary, and } \\
\text { Test walks. These are } \\
\text { recommended for } \\
\text { different situations and } \\
\text { types of space to } \\
\text { accurately measure } \\
\text { pedestrian uses of } \\
\text { space. }\end{array}$ & $\begin{array}{l}\text { Looking to } \\
\text { measure } \\
\text { pedestrian use of } \\
\text { public spaces, } \\
\text { including overall } \\
\text { numbers of users } \\
\text { and patterns of } \\
\text { use: how do } \\
\text { people use this } \\
\text { space? How } \\
\text { usable or inviting } \\
\text { is this space for } \\
\text { pedestrians? }\end{array}$ & $\begin{array}{l}\text { Gehl's methods of counting, photographing } \\
\text { and tracking are the most applicable to this } \\
\text { situation. Counting involves headcount of } \\
\text { stationary people, and measuring } \\
\text { pedestrian flow by counting people; these } \\
\text { activities should be done throughout the day } \\
\text { for } 10 \text { mins/hour. Tracking includes following } \\
\text { walking speed, by selecting every } 3^{\text {rd }} \\
\text { person's path between two points, roughly } \\
100 \text { m long. Photographing involves taking } \\
\text { photos of how people use the space to } \\
\text { illustrate numerical observations. Methods } \\
\text { were not adhered to strictly, but I noted the } \\
\text { ability to perform them in the space, and } \\
\text { photographs were taken. }\end{array}$ \\
\hline
\end{tabular}

Figure 5. Overview of Observational Methods. 
Lynch

Kevin Lynch's book The Image of the City (1960) gives a strong methodological framework to evaluate city form and structure. The Image of the City provides what is likely the most widely used way of observing and classifying urban elements and how they are used. The book's method includes five key elements with which to classify city elements: nodes, landmarks, districts, edges and paths. These elements are used in mapping exercises with residents and users of neighbourhoods to determine what parts of the community are used in which way by those who live, work and recreate there. Maps showing where residents identify these elements illustrate use patterns; while seen as standard practice now, this mapping technique was revolutionary when Lynch first introduced it in the 1960s. The maps created by people are meant to highlight the legibility (or lack thereof) of the built environments and neighbourhoods within a city. The five elements are a way for users to code and analyze how the elements of these environments are used.

J. Jacobs

Jane Jacobs, as stated earlier, wrote one of the first critiques of the lack of direct urban observation present in planning practice of the 1950s. She was an activist who critiqued the method of planners, particularly Mumford. Her method was largely exploratory, without having a specific end goal in sight, and called for a better understanding of what she calls a "ballet of the good city sidewalk" (Jacobs, 1961, p. 50), referring to the seemingly chaotic movement of people and goods in cities that are actually signs of a successful and busy streetscape. Her method was bottom up and inductive, giving specific elements of city blocks and neighbourhoods but not offering particular methods for observation of these places.

Whyte

William $\mathrm{H}$. Whyte was one of the pioneers of urban observation, focusing on quantitative methods. His 1980 book The Social Life of Small Urban Spaces describes 
the methods he pioneered in New York City, where he was tasked with determining what differentiated the successful public plazas from the unsuccessful ones. His methods focus on timed observations, noting the location and duration that people sit in different places or stop in conversation. His techniques included video recording and direct observation, with systematic notation techniques, recording activity in public spaces on maps with grids and symbols.

\section{A. Jacobs}

Allan Jacobs' Looking at Cities (1985) is regarded as one of the seminal planning works. Looking at Cities offers clues to look for when looking at different cities; it focuses on observation techniques and signs to look for when observing cities. The book emphasizes the importance of architectural styles, street layout, traffic, people, activities, and types of businesses. The opening question from this paper is from this book, which also includes a chapter in which the author visits a series of cities in Italy in order to test his set of clues within an unfamiliar environment. He determines that they do translate, but his methods include interviews with locals who point him towards the best neighbourhoods to study. He then verifies his findings afterwards with local experts to determine their success. This implies that the clues work, but still require coordination with local experts before and after visiting sites to ensure accurate findings. If he wasn't pointed in the direction of important areas of the city, his findings would have been much less successful.

Gehl

Jan Gehl has created the most recent method discussed here. He is still a practicing consultant, and many of the methods I will use are from his most recent book, How to Study Public Life, published with Birgitte Svarre in 2013. Gehl and Svarre refer to eight particular methods for urban observations: Counting, Mapping, Tracing, Tracking, Looking for traces, Photographing, Keeping a diary, and Test walks (2013, p. 24). Gehl focuses on how people move throughout the spaces- how many people there 
are, how fast they are moving, and what paths they take to get there form the majority of his observations. For example, test walks involve the researcher walking potential pedestrian routes in order to determine what the pedestrian environment is like (is it easy to navigate? frustrating with many sets of traffic lights?).

What all of these methods share is a belief that planners are able to learn about how spaces function through observing how people interact with these spaces. The larger question that this investigation attempts to begin to answer is whether this works in places where planners are unfamiliar with the people, their culture, or the spaces themselves.

\section{Policy Framework}

The policy process is what largely dictates how and when planners plan the way they do, particularly for municipal planners. The processes are complex and involve participation at various stages by different people. Zoning By-Law Amendments and Official Plan Amendments are the two most common policy processes, and the process for each is shown on the pages following.

Beyond potential observational methodologies, the way planners in Ontario evaluate a site is by determining relevant planning policies. In the Greater Toronto context, this requires knowledge of the overarching Planning Act, Provincial Policy Statement (PPS) and Growth Plan for the Greater Golden Horseshoe (GPGGH), as well as the relevant Official Plan (OP) policies (single tier or upper and lower) and Zoning By-law (ZBL). 


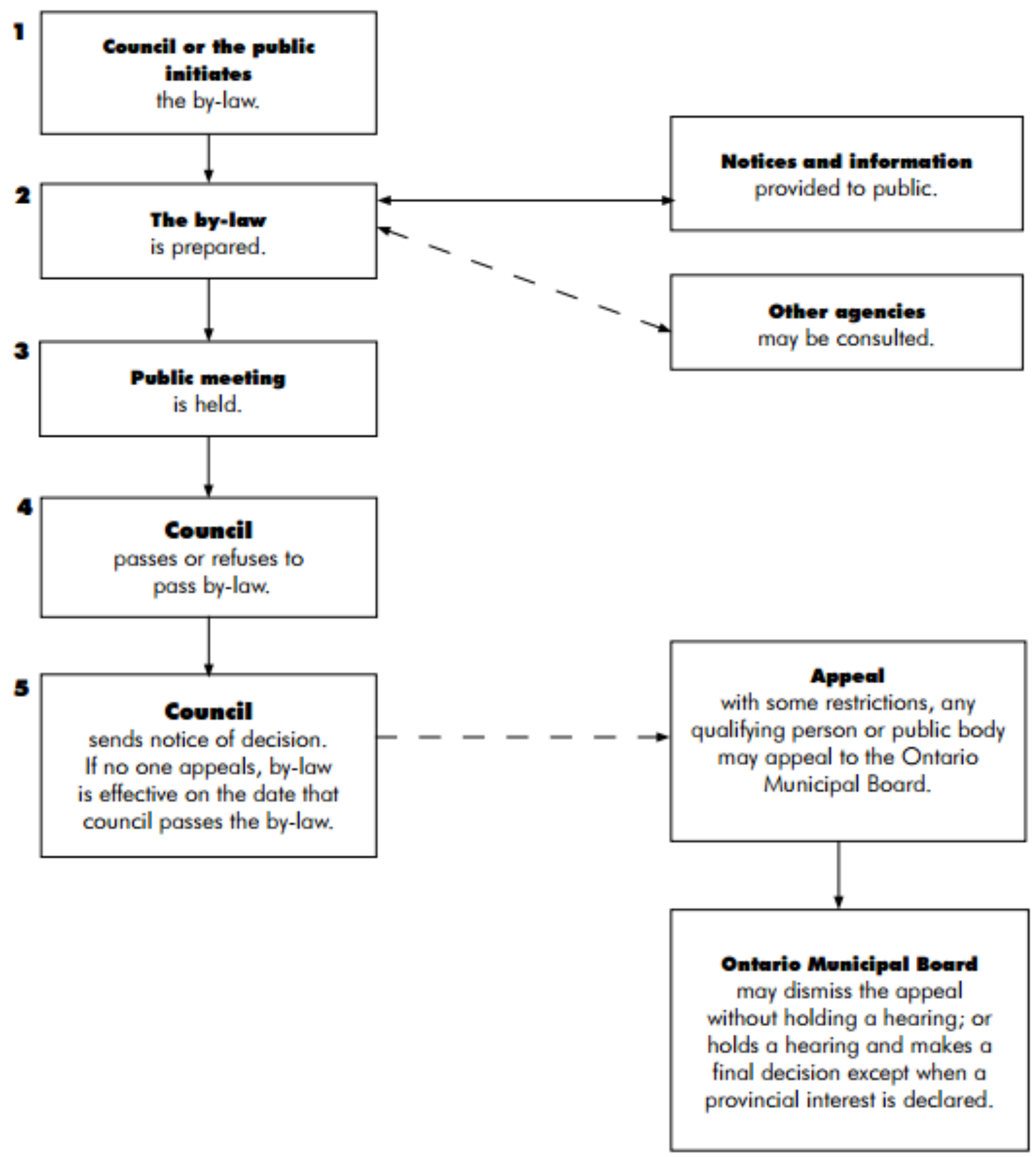

This flowchart focuses on the basic process - some steps are not shown

Figure 6. Zoning By-Law Process (Source: Citizens' Guide 3: Zoning By-Laws, MMAH) 
The Official Plan Process

(Plans exempt from approval)

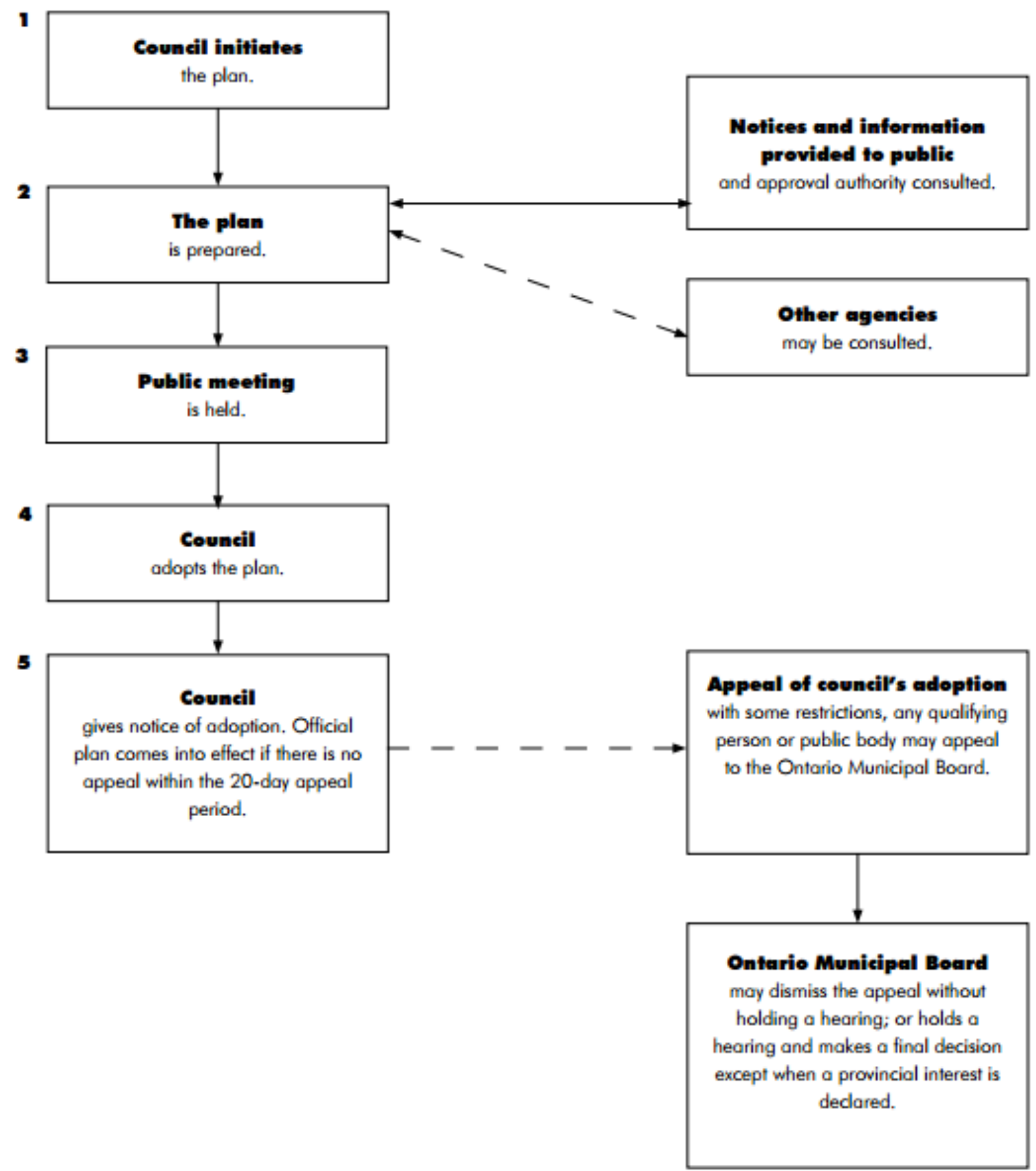

This flowchart focuses on the basic process - some steps are not shown

Figure 7. Official Plan Process (Source: Citizens' Guide 2: Official Plans, MMAH) 


\section{Adaptations of Standard Method}

Because this project is meant to be a proxy for planners' initial level of analysis, I will adapt the methodologies to ones which I am able to complete within a short time frame, and with no prior knowledge of the community. Often, planners are required to make decisions and recommendations for places with which they have only very cursory interactions. The methods undertaken at Pacific Mall were meant to determine what could be observed, more than actually observing it. This method is covered in the Overview of Observational methods (Figure 5).

\section{Site Observation Method}

The site visits were carried out on two separate occasions in the month of February 2015. Before these site visits, I attempted to remain relatively ignorant to details regarding Pacific Mall, only accessing basic information through their website to determine their hours of operation and download site maps to use in field observations. Further, I researched the Zoning By-Law and Official Plan information. I had planned a site visit for the second week of February, but was informed that this was the week of Chinese New Year and would therefore give a biased view of the use characteristics of the Mall.

The first visit occurred the day after a serious winter storm, which resulted in the loss of power throughout the surrounding area. I arrived at approximately $2 \mathrm{pm}$ on a Tuesday. When I arrived at the mall many of the stores were still without power and therefore closed; there were very few people in the mall. I made only observations regarding the general layout and details regarding the building, as observations about people and use of space were impossible. The second visit occurred on the following Sunday, shortly after the Mall opened at $11 \mathrm{am}$. This visit was more fruitful, with many more users in the space and most of the stores and food court stalls open. 


\section{Meeting with Zhixi Zhuang}

After completing the site visits described above, I met with Dr. Zhixi Zhuang to compare methods. I presented her with my initial observations and overall takeaways of Pacific Mall, and she informed me what the use of these methods I missed. We discussed initial conclusions, and what planners could learn from this research. I integrated this feedback in the findings and discussion in the section that follows. 


\subsection{Findings and Discussion}

\section{Policy Context}

Planning practice in Ontario requires an understanding of the policy hierarchy that applies to each site. This includes high-level provincial policies, particularly the Provincial Policy Statement (PPS) and the Growth Plan on the Greater Golden Horseshoe (GPGGH), as well as site or area specific municipal policies, predominantly Official Plans (OPs) and Zoning By-Laws (ZBLs). Initial site observation includes a policy analysis to determine whether a site is in line with current policy documents.

\section{Provincial Policy Statement}

A high-level policy document, the PPS requires development to be consistent with PPS policies. In proximity to GO and TTC transit options, Pacific Mall is consistent with transit-oriented development, called for in section 1.1.3.2, but with 1500 parking spots it also clearly markets towards car-oriented traffic (Provincial Policy Statement, 2014). Generally, a regional servicing mall located in close vicinity to transit options is consistent with PPS policies.

Growth Plan for the Greater Golden Horseshoe

Mandated by the Places to Grow Act (2005), The GPGGH classifies the site as within the Region of York. Pacific Mall is located in between two Urban Growth Centres: Markham Centre, located at Highway 7 and Warden Ave. and Scarborough Centre, located at McCowan Rd. and the 401. Because it is located outside of these Urban Growth Centres, the Pacific Mall site is not subject to intensification targets, and therefore conforms with GPGGH policies, which apply on a regional level.

\section{Official Plans}

Markham is a lower-tier municipality within the upper-tier regional municipality of York. Therefore, sites in Markham must conform to the Official Plan of Markham as well as York's (Markham's OP should conform to York's, as York is the upper-tier municipality). The Region of York's OP classifies the site as an "Urban Area", but not 
within Markham's regional centre (located at Highway 7 and Warden Ave., Map 1: Regional Structure). The City of Markham's Official Plan designates Pacific Mall as Commercial. Section 9.15 Milliken Site Specific Policies also apply to the site. Section 9.15.3.1 applies in particular to the Pacific Mall development.

\subsubsection{1: Land Use Objective}

The Local Centre of Milliken Centre is intended to:

a) provide a focal point for the larger Milliken community, through the implementation of a pedestrian, transit supportive development pattern; and

b) integrate a balance and diversity of residential, retail, office and public uses, at transit-supportive densities adjacent to the GO station.

Generally, the site conforms to both Official Plan policies in that it supports the policy goals of the region as a whole and Milliken centre more specifically. Zoning By-Law

The site is zoned SC2-S: Special Commercial Two - Special Zone under City of Markham by-law 47-85, with Site Specific Permitted Uses under By-law 241-96. This By-law allows for restaurants, retail stores, service shops, trade and convention centres, day cares, commercial schools, dry cleaning establishments, health centres, indoor recreational establishments, hotels and motels, offices and places of worship. Pacific Mall conforms to the current zoning by-law requirements, containing only allowed uses within the by-law.

Overall, the site conforms to relevant policy documents. Overall, the site is consistent with the PPS, conforms to the GPGGH, to both OP policies as well as the current Markham zoning by-law. This means that the site use, a regionally focused mall, is in line with the relevant planning policies. While municipal policies have been updated since the construction of the mall, because this site is in line with policies, it is a use which reflects highest/best use given the current policy framework. 


\section{"Learning to See" - Assessing the Utility of Common Planning Methods}

\begin{tabular}{|c|c|c|}
\hline Author & What the Method Taught Me & What the Method Missed \\
\hline Lynch & $\begin{array}{l}\text { By noting heavily used areas, nodes of } \\
\text { activity were easy to determine, } \\
\text { including the escalators and food } \\
\text { courts on the second level. The stage } \\
\text { on the first floor was easily the largest } \\
\text { element and most easily } \\
\text { identifiable/locatable due to its central } \\
\text { location; I therefore coded it as the } \\
\text { major landmark on the first floor, } \\
\text { whereas the entrance to the Heritage } \\
\text { Town on the Second Floor was the most } \\
\text { identifiable landmark there. }\end{array}$ & $\begin{array}{l}\text { By completing Lynchian analysis myself, } \\
\text { I was unable to determine legibility for } \\
\text { the intended users, only myself (and } \\
\text { assumptions based on watching people } \\
\text { use the space). Missed the important } \\
\text { part of Lynch' analysis that looks at how } \\
\text { legible spaces are from user's } \\
\text { perspective. }\end{array}$ \\
\hline J. Jacobs & \multicolumn{2}{|c|}{$\begin{array}{l}\text { Because Jacobs gave little actual advice around observational techniques, and the } \\
\text { context of an indoor mall is very outside of her scope, I will not focus on her } \\
\text { methods for this case study. }\end{array}$} \\
\hline Whyte & $\begin{array}{l}\text { Whyte's criteria of sitting, food, retailing } \\
\text { and toilets were similarly easy to record. } \\
\text { The obvious abundance of retail aside, } \\
\text { the lack of seating and toilets noted on } \\
\text { the ground floor did appear to make it } \\
\text { less successful as a public space, with } \\
\text { people gravitating towards areas with } \\
\text { these amenities. The question of what } \\
\text { impact this has on the ground floor } \\
\text { retail is one worth considering. }\end{array}$ & $\begin{array}{l}\text { Whyte's methods captured general use } \\
\text { patterns and the absence or presence of } \\
\text { the different elements. I am left } \\
\text { wondering about whether these } \\
\text { elements translate universally- and } \\
\text { therefore whether the lack of seating on } \\
\text { the ground floor is a) intentional or b) } \\
\text { impacts the public space negatively. }\end{array}$ \\
\hline A. Jacobs & $\begin{array}{l}\text { Allan Jacobs' clues around architectural } \\
\text { style, level of repair, and people were } \\
\text { straightforward to note, as were clues } \\
\text { regarding signs and the commercial } \\
\text { centre. Clues about people, as } \\
\text { mentioned by Jacobs himself, are } \\
\text { difficult to make conclusions based on. } \\
\text { General observations based on age, } \\
\text { group size and dynamic can be noted } \\
\text { but assumptions beyond this would be } \\
\text { just that: assumptions. }\end{array}$ & $\begin{array}{l}\text { Jacobs' observations, similar to Whyte's, } \\
\text { are possible to make general } \\
\text { observations about, but harder to make } \\
\text { assumptions regarding what these clues } \\
\text { mean. Jacobs spoke about the } \\
\text { universality of these clues, but is that } \\
\text { really the case? }\end{array}$ \\
\hline Gehl & $\begin{array}{l}\text { Gehl's methods are the most focused } \\
\text { on behavioural evaluations of how } \\
\text { people use the space. It was possible, } \\
\text { as it would be in most environments, to } \\
\text { count and track people's movements } \\
\text { through the space. However, this led to } \\
\text { questions about what conclusions to } \\
\text { draw from the data once it was } \\
\text { available. }\end{array}$ & $\begin{array}{l}\text { I could have stayed all day, taking } 10 \\
\text { minute observations of walking speed of } \\
\text { pedestrians, but I wasn't sure if that } \\
\text { would tell me the same thing as it would } \\
\text { about walking speeds in a Western } \\
\text { context. So, similarly to my questions } \\
\text { about Whyte's methods, does walking } \\
\text { speed translate across the world? How } \\
\text { do use patterns differ? I felt as though I } \\
\text { lacked the necessary information to } \\
\text { draw conclusions regarding this. }\end{array}$ \\
\hline
\end{tabular}

Figure 8. Overview of Findings.

In general, it was possible to observe the built environment and people's

movements with it, as dictated by the observational methods. These included the 
number of people, general demographics, architectural details of the space, level of maintenance, pedestrian traffic patterns, and walking speed.

Largely, the difficulties in observation revolved around cultural understandings and relevant historical knowledge of the space. Specifically, this led to questions around interpreting the information observed. Most questions around this arose after initial observations, when attempting to assign value judgements to initial observations.

Lynch's analysis was the most familiar to me, having completed similar analysis for coursework. By noting heavily used areas, nodes of pedestrian activity were easy to determine. These included the escalators, central stage area of the ground floor, and food courts on the second level. The stage on the first floor was easily the largest element and most easily identifiable and locatable due to its central location, I therefore coded it as the major landmark on the ground floor, while the entrance to the Heritage Town on the second floor was the most identifiable landmark there. As it was completed by me and not the intended site users, this analysis missed determining the legibility of the space for the intended user.

Whyte's criteria of sitting, food, retailing and toilets were also easy to record. The obvious abundance of retail aside, the lack of seating, food and toilets found on the ground floor did appear to make it less successful as a public space, with people gravitating towards areas on the second floor with these amenities. The question of what impact this has on the ground floor retail is an important one.

Allan Jacobs' clues around architectural style, level of repair, and people were straightforward to note, as were clues regarding signs and the commercial centre as a whole. Clues about people, as mentioned by Jacobs himself, are difficult to make conclusions on. While it was possible to make general observations about the age, group size and dynamic of the mall users, because of my lack of cultural understanding it was difficult to make conclusions based on this information. 
Gehl's methods are the most focused on behavioural evaluations of how people use the space. It was possible, as one would assume, to count and track people's movements through the space. However, this led to questions about what conclusions to draw from the data once it was available. I could have stayed all day, taking 10 minute long observations of the walking speed of pedestrians, but I wasn't sure if that would tell me the same thing as it would about walking speeds in a familiar context. Does walking speed translate across the world? How do use patterns differ? I felt as though I lacked necessary information to draw conclusions from this data.

\section{Observations about Pacific Mall}

The mall was difficult to navigate for me, because storefronts are enclosed in glass and in a tight grid system, which made triangulation difficult. Rows are organized into streets and avenues, but the absence of overhead signage makes this difficult to read. There is very little seating on the ground floor, with only massage chairs set up in the central area, benches along the west wall, and window bays used for seating along the south wall. The available seating is well used, and the food courts on the second floor are close to full. There are also no bathrooms on the main floor, only in the basement proximate to the parking garage or on the second floor. There were more people and families on the second floor, which seemed related to the availability of food, seating and entertainment (there is an arcade off the main area).

The architecture seems inconsistent- the "Pacific Heritage Town" is advertised as a Pacific style market, but I could only find references to Pacific Mall when I researched this style. The style seemed overly ornate for the rest of the mall- there are Terracotta Warrior statues stationed haphazardly outside the bathroom entrances, for example. Little detail has been paid to the detailing on the ground floor- the ceilings are finished with grey paint and little effort has been put into making it into a space for congregation. This is in direct contrast to the second floor, as well as Market Village to the east. Market Village is set out in a more legible way, with a circular walkway 
surrounded by stores on either side, centred around a large central food court and stage. There was a contest occurring on the stage during our site visit on Sunday morning, and the food court was busy with people.

The users of the space appeared to be largely Asian families, with the food court appearing more popular than the retail, although this could have been specific to the day and time of observation. It would be better to go back at different point throughout the day and week to better reach conclusions about the user base. Standardized and minimal signage on the ground floor gave a uniform impression of the space, while the layouts and decor within each store varied.

The type of stores and services available indicates that the mall is serving a regional market, and the design of the heritage section seems to imply that the customer base are tourists, because of the Chinese focus of the mall.

\section{What I correctly identified}

In discussing my conclusions from Pacific Mall with Dr. Zhixi Zhuang, I was able to confirm initial observations, and determine what important information my observations missed. This information will inform my conclusions and next steps.

My observations about the legibility of the space were confirmed, in that Zhuang agreed that the ground floor retail space is illegible and difficult to navigate. The grid pattern was likely created to maximize profit for the developer, in that they increase the number of sellable units and rentable square footage by using the grid pattern. Further, she confirmed that the lack of effort put into the public mall amenities is noticeable and in contrast to both the second floor and adjacent Market Village, which both have actively well-used public gathering places.

\section{What I Missed}

My observations, while picking up on the physical details of the space, failed to pick up on important details about the space that are historical and cultural in nature. Specifically, the observations failed to pick up on the fact that the building's 
architectural style reflected the previous use of the site, Cullen Country Barns, as well as apparently referencing St. Lawrence Market's form. Further, while I observed that the majority of the users of the space were Asian, I was unable to detect the different subsets within this group. Specifically, Chinese people originating from Hong Kong versus from those from Mainland China; these groups have widely different cultural backgrounds, spoken language, and retail desires. Because of this cultural variation, including entertainment, clothing tastes and dietary wishes, these groups form two entirely different market segments, desiring different retail stores and products. Additionally, first and second generation immigrants have different tastes and language abilities, with second generation immigrants often retaining Chinese cultural habits but losing language abilities. This further segments the group I had erroneously grouped together.

Another important piece of information that was missed by observation alone was around store ownership. Pacific Mall operates largely through condominium style ownership of stores, which I was aware of prior to site visits. The nuances around this fact were lost however, in that many of the stores are subleased by their owners. This means that there is no centralized control over commercial rental rates, which are up to individual store owners to determine, and can therefore fluctuate greatly; this could also explain the high number of stores offering the same product (largely cellphone accessories). This ownership structure is apparently more attractive to foreign investors as a way to attain certain types of visas; because the ultimate goal of these investors is the visa, profits are less important to these store owners which can mean vendors selling goods under market value, which can in turn impact the prices of those around them. These market forces, important cultural differences, and historical information not immediately available greatly impact the environment and users of the space, but are not able to be known through observation alone. 


\subsection{Conclusions}

Based on my analysis of the observational methodologies and their utility in the Pacific Mall case study, I have created conceptual questions, a short guide for practicing planners, and determined next steps regarding the continued utility of these methods within the contemporary urban environments planners find themselves on a regular basis.

\section{Five Conceptual Questions About Observational Methods}

I have devised five conceptual questions around these methods, based largely on the information that my observations missed. What are the most important pieces we are missing when we attempt to read a landscape we are unfamiliar with?

\section{Legibility}

The question of legibility, or what Lynch refers to as imageability (1960, p. 9), is the biggest question around reading spaces that are unknown. The most important question to answer around this idea is: Is this space legible for the intended user? In order to answer this, we must first answer who the intended user is, and what legibility looks like to them. The first question is relatively easy to answer, but the second is very difficult. If the space isn't legible to me, how can I decipher whether it is legible for the intended user? The idea of legibility also begs the question about how much about the culture we need to know before we arrive. Jacobs determined his clues translated to an unknown Italian context, but only after he was directed by locals to the best neighbourhoods to look for clues. Would his clues work as well without this culturally derived information? Further, can you have expertise over a space that isn't yours?

\section{Cultural Understanding and Communication}

As evidenced from the Pacific Mall case study, cultural understandings are very difficult to assemble through observation, particularly when observing cultures that you aren't familiar with. It is therefore important to understand these considerations through other means. This begs the question: is there a way for planners to better 
understand these cultural differences? If there is, do we have a duty to integrate these understandings into the way we plan these places? How can these understandings be better communicated from the community to planners, and from planners into the planning process?

\section{Differences}

The concept of differences is fundamental, but one that seems often forgotten. Planning for a breadth of users and understanding who the intended users are is difficult. Ultimately, it requires knowledge of who uses the space, what their needs are, and how to plan appropriately for these needs. Simply noting that these differences exist is an important first step, and one that raises questions about how we then move to understand these differences and adequately plan for them.

Importantly, as with the differentiation between Pacific Mall's shoppers from Hong Kong and Mainland China, there are often intragroup differences that can be large in scale, but less obvious to outside observers. Baum discusses this concept (2000), in that differences between groups are often played up and those within groups are downplayed. In reality however, this is often not the case, with cultural differences within groups as large as between them. Culture is important to note but is more complicated than defining people by their racial categories (Baum, 2000, p.117).

\section{Teaching/Education}

The questions of what planners are learning before they begin their practice is an important one. There is clearly a disconnect between planning methodology and the tools needed to understand unknown spaces. Are planners asking the right questions about what we know and how we practice in these spaces, both within the academic realm and in applied practice?

5. Government Responsibility in an Time of Austerity

Finally, the question of where responsibility falls to rectify issues with the current planning process is important. Planners clearly need to build in time to learn about 
other cultures. This is true as planners are being increasingly asked to plan for spaces within other cultural contexts, and often in Western contexts that are meant to serve a wide range of users from different cultures. The same thing can be said for other considerations as well - we need to build in time to do better site visits for ecological and cultural issues. The question of diversity and the availability of resources is one that comes back to resource allocation; if planners taking this extra time for analysis, someone must pay the bill. Whose responsibility is it and whose should it be?

\section{What does this mean for practitioners?}

What do all of these questions mean? Particularly, what do these questions mean for the practicing planner who is increasingly faced with these unknown environments? With so many questions, the only surety is that new tools are needed to better understand unknown landscapes such as these. Important takeaways will begin to help practitioners keep in mind the challenges raised above as they encounter the unknown.

The observational methods planners currently have in their toolkit appear to provide a good overview of observable clues and indicators of how a space is used. These observational methods did not miss physical clues within the environment, but there were nonmaterial factors that are inherently impossible to understand through observation alone, including historical and cultural knowledge; the question becomes how planners learn about these details that are vital to planning places. Instead of altering the existing observational methods then, it appears there is a filter missing that is required when a planner goes outside of their environment to plan unknown spaces. This practical guide for planners attempts to fill that gap, where possible.

\section{A Guide for Planners: Things to Consider When Encountering Unfamiliar Places}

1. Understanding the Culture of the Place

The idea of understanding the culture of place is true for all places, including ones that are from a cultural context similar to your own, but more important when 
attempting to understand one from outside your current understanding. What does this place mean for the people who use it? What would potential changes mean for what the space means for these users?

\section{Understanding the Users of the space}

Who are the intended users of this space? Are they the same people who are currently using the space? Was the space originally designed for them? If an amendment to the space is being proposed, how will it affect this user? While these are difficult questions to answer, even considering them is an important first step for planners.

3. Legibility- Is the space legible for the intended user?

Determining whether the space is legible for yourself is important, as with any space. However, it is important to also consider whether or not you are the intended user, and whether or not the site is legible for them. First, determine or attempt to determine who the intended user is. Second, work to determine if the space works for them. This determination can be done by speaking to people if possible, or by observing how they use the space if interviews are not feasible.

\section{Changing the Content of Planning Reports}

Is there additional information that should be added to reports in order to better address these stories of place or histories? Planning reports currently give physical site context details, but should they also include cultural or historical context? If you are planning for a municipality, consider integrating this information into staff reports. As a consultant, consider adding this information to the site context you supply to your clients. 


\subsection{Next Steps}

Clearly there is a current disconnect between how planners analyse spaces and the information necessary to reach the best planning decisions. In order to correct for this divide, changes are required across the planning field, including planning education, governance changes, and within the planning practice itself. First, further research is necessary to further analyze these questions and hone the guide for planners.

\section{Planning Schools}

A change to how planners are taught to observe and understand spaces is fundamental to changing how future planning will happen. By adding a nonphysical understanding of place to pedagogical practice, planning students can better understand the landscapes they will plan.

\section{Government Resources}

Changes in planning practice, especially for municipal planners, come from governance changes and/or flexibility. In order to allow planners to understand places, how can we make better rules to allow that to happen? By permitting the time and space to better understand places, governments could help to ensure better long term for a variety of users of urban spaces.

\section{Planning Practice}

Naturally, the most fundamental changes to this process will occur from within the planning practice itself. Getting planners to understand the need to plan for more than just the physical clues will change how urban environments are analyzed and therefore planned for. A natural first step is the creation of a toolkit for planners to remind them of these subtleties before they attempt to plan, particularly for places with which they are unfamiliar. 
What does this all mean? These observational methods and the application of them in varying cultural contexts and configurations of built form raise important questions for both planning research and applied planning practice. Clearly, additional analysis is required beyond observation to understand unfamiliar cultural spaces. While this realization is more apparent, the question of how to address this additional analysis is more nuanced and much less clear. Whereas practical tips are briefly discussed, offering high-level fundamental considerations for planners, further research is required to offer a better understanding of how planners can better understand the unknown places they increasingly encounter. 
References

Abramson, D. B. (2005). The "Studio Abroad" as a Mode of Transcultural Engagement in Urban Planning Education A Reflection on Ten Years of Sino-Canadian Collaboration. Journal of Planning Education and Research, 25(1), 89-102.

Alexander, C., Ishikawa, S., \& Silverstein, M. (1977). A pattern language: towns, buildings, construction.

Appleyard, D. (1970). Styles and methods of structuring a city. Environment and behavior.

Baum, H. S. (2000). Culture matters-but it shouldn't matter too much. Urban Planning in a Multicultural Society. Westport, CT: Praeger, 115-136.

Bentley, I. (Ed.). (1985). Responsive environments: a manual for designers. Routledge. Burayidi, M. A. (Ed.). (2000). Urban planning in a multicultural society. Greenwood Publishing Group.

Burayidi, M. (2003). The Multicultural City as Planners' Enigma. Planning, Theory and Practice. 4 (3): 259-273.

Carmona, M., \& Punter, J. (2013). The design dimension of planning: theory, content and best practice for design policies. Routledge.

Consiglio, A. (2012, December 25). No stopping shopping at Pacific Mall on

Christmas. The Toronto Star. Retrieved from:

http://www.thestar.com/news/gta/2012/12/25/no_stopping_shopping_at_pacific_ mall_on_christmas.html

Dunham-Jones, E., \& Williamson, J. (2011). Retrofitting Suburbia, Updated Edition: Urban Design Solutions for Redesigning Suburbs. John Wiley \& Sons.

Ford, L. R. (1999). Lynch revisited: New urbanism and theories of good city form. Cities, 16(4), 247-257.

Forsyth, A. (2012). Defining suburbs. Journal of Planning Literature, 27(3), 270-281.

Gehl, J. (2010). Cities for people. Island Press. 
Gehl, J., \& Svarre, B. (2013). How to study public life. Island Press.

Gordon, D. L., \& Janzen, M. (2013). Suburban nation? Estimating the size of Canada's suburban population. Journal of Architectural and Planning Research,30(3), 197.

Hayden, D. (1997). The power of place: urban landscapes as public history. MIT Press. Jacobs, A. (1985). Looking at cities. Harvard University Press.

Jacobs, A.(1993). Great streets. Massachusetts Institute of Technology, USA.

Jacobs, J. (1961). The Death and Life of Great American Cities. Vintage.

Jeffres, L. W., Bracken, C. C., Jian, G., \& Casey, M. F. (2009). The impact of third places on community quality of life. Applied Research in Quality of Life,4(4), 333-345.

Kane, L. (2013, August 19). Pop-up city planner workshops across Toronto to address city's changing neighbourhoods. The Toronto Star. Retrieved from: http://www.thestar.com/news/city_hall/2013/08/19/popup_city_planner_worksho ps_across_toronto_to_address_citys_changing_neighbourhoods.html

Leccese, M., \& McCormick, K. (2000). Charter of the new urbanism. McGraw-Hill Professional.

Loukaitou-Slideris, A. (1995). Urban form and social context: cultural differentiation in the uses of Urban Parks. Journal of Planning Education and Research. 14(2).

Lynch, K. (1960). The image of the city (Vol. 11). MIT press.

Lynch, K. (1984). Good city form. MIT press.

Markham. City Planning Division (1985). Markham Zoning By-Law 47-85.

Markham. (1996). Markham By-Law 214-96.

Markham. City Planning Division (2014). Markham Official Plan: Section 9.15.

Mehaffy, M. W. (2008). Generative methods in urban design: a progress assessment. Journal of Urbanism, 1(1), 57-75.

Milgram, S. (1974). The experience of living in cities. Crowding and behavior, 167, 41. 
Montgomery, C. (2013). Happy city: transforming our lives through urban design. Macmillan.

Oldenburg, R., \& Brissett, D. (1982). The third place. Qualitative Sociology,5(4), 265-284.

Ontario. (2006). Growth Plan for the Great Golden Horseshoe

Ontario. (2006). Growth Plan for the Great Golden Horseshoe: Schedule 4

Ontario. (2008). Size and Location of Urban Growth Centres in the Greater Golden Horseshoe: Section 3.

Ontario. (2014). Provincial Policy Statement.

Places to Grow Act (S.O. 2005, c.13).

Owens, P. M. (1993). Neighborhood form and pedestrian life: Taking a closer look. Landscape and urban planning, 26(1), 115-135.

Pacific Mall, (n.d.). Pacific Mall. Retrieved from: http://www.pacificmalltoronto.com/

Phelps, N. A., Wood, A. M., \& Valler, D. C. (2010). A postsuburban world? An outline of a research agenda. Environment and Planning A, 42(2), 366-383.

Project for Public Space, (2000). How to turn a place around. Projects for Public Space Inc, 225-232.

Qadeer, M., Agrawal, S. and Lovell, A. (2010). Evolution of ethnic enclaves in the Toronto Metropolitan Area. 2001-2006. Journal of International Migration and Integration.Vol. 11 No. 3. Pp 315-339.

Qadeer, M., \& Kumar, S. (2006). Ethnic enclaves and social cohesion.Canadian Journal of Urban Research, 15(2), 1-17.

Rosenbaum, M. S., Ward, J., Walker, B. A., \& Ostrom, A. L. (2007). A cup of coffee with a dash of love an investigation of commercial social support and third-place attachment. Journal of Service Research, 10(1), 43-59.

Sandercock, L. (2000). When strangers become neighbours: Managing cities of difference. Planning Theory \& Practice, 1(1), 13-30. 
Sassen, S. (2001). The global city: new york, Iondon, tokyo. Princeton University Press. Southworth, M., \& Owens, P. M. (1993). The evolving metropolis: studies of community, neighborhood, and street form at the urban edge. Journal of the American Planning Association, 59(3), 271-287.

Smith, G., E. Warner, M., Fioretti, C., \& Meschiari, C. (2014). Rome undergraduate planning workshop: A reflexive approach to neighborhood studies. Planning Theory \& Practice, 15(1), 9-25.

Stedman, R. C. (2002). Toward a social psychology of place predicting behavior from place-based cognitions, attitude, and identity. Environment and behavior, 34(5), $561-581$.

Talen, E. (2005). Evaluating good urban form in an inner-city neighborhood: An empirical application. Journal of Architectural and Planning Research, 204-228.

Talen, E. (2011). Sprawl Retrofit: sustainable urban form in unsustainable places. Environment and Planning-Part B, 38(6), 952.

Tibbalds, F. (Ed.). (2012). Making people-friendly towns: Improving the public environment in towns and cities. Taylor \& Francis.

Tolbert, C. M., Lyson, T. A., \& Irwin, M. D. (1998). Local capitalism, civic engagement, and socioeconomic well-being. Social Forces, 77(2), 401-427.

Trancik, R. (1986). Finding lost space: theories of urban design. John Wiley \& Sons.

Turcotte, M. (2008). Dependence on cars in urban neighbourhoods. Canadian Social Trends, 85, 20-30.

Turcotte, M. (2009). Life in metropolitan areas: are suburban residents really less physically active?. Canadian Social Trends, (87), 34-43.

York Region (2010). York Region Official Plan: Section 1.1.3.2.

York Region (2010). York Region Official Plan: Map 1: Regional Structure.

Wang, S. and J. Zhong. 2013 Delineating Ethnoburbs in Metropolitan Toronto. Working Paper No.100, Toronto: CERIS. 
Ware, C. (2012). Information visualization: perception for design. Elsevier.

Whyte, W. H. (1980). The Social Life of Small Urban Spaces.

Zhuang, Z. 2013. Rethinking Multicultural Planning: An Empirical Study of Ethnic Retailing. Canadian Journal of Urban Research. 22 (2), 90-116. 